\title{
NUEVAS TENDENCIAS DE ORGANIZACIÓN CRIMINAL Y MOVILIDAD GEOGRÁFICA. APROXIMACIÓN GEOPOLÍTICA EN CLAVE DE INTELIGENCIA CRIMINAL
}

\author{
Daniel Sansó-Rubert ${ }^{1}$ \\ Universidad de Santiago de Compostela
}

\begin{abstract}
Resumen:
El artículo pretende ofrecer una introducción explicativa sobre la tipología de relaciones posibles en el ámbito criminal organizado, los modelos de organización y su movilidad geográfica, a través de la conjunción de las disciplinas de la criminología, la geopolítica y la inteligencia criminal. El estudio persigue un doble objetivo: por un lado, aportar una reflexión que favorezca la apertura de líneas de investigación sobre la diversidad morfológica de las organizaciones criminales, las alianzas forjadas entre ellas, así como su expansión territorial, por otro, maximizar el conocimiento obtenido para apoyar la adopción de decisiones estratégicas, de políticas públicas y la detección de vulnerabilidades explotables para el desarrollo de estrategias de intervención.
\end{abstract}

Palabras clave: Delincuencia organizada, redes criminales, organizaciones criminales, inteligencia criminal, geopolítica, criminología

Titulo en Inglés: "New Tendencies in Criminal Organization and Geographical Mobility. Geopolitical Approach and Criminal Intelligence"

\section{Abstract:}

This article aims to provide an explanatory introduction to the types of possible relationships in the organized criminal field, organizational models and geographical mobility, through the conjunction of the disciplines of criminology, geopolitics and criminal intelligence. The study has two objectives: first, to provide a reflection that favors the opening of research on the morphological diversity of criminal organizations, the alliances forged between them as well as their territorial expansion, and second, maximizing the knowledge in order to support the strategic decision-making, public policy and detection of exploitable vulnerabilities for the development of intervention strategies.

Keywords: Organized crime, criminal networks, criminal organizations, criminal intelligence, geopolitics, criminology.

\section{Copyright (C) UNISCI, 2016.}

Las opiniones expresadas en estos artículos son propias de sus autores, y no reflejan necesariamente la opinión de UNISCI. The views expressed in these articles are those of the authors, and do not necessarily reflect the views of UNISCI

\footnotetext{
${ }^{1}$ Daniel Sansó-Rubert es Secretario del Centro de Estudios de Seguridad (CESEG).Universidad de Santiago de Compostela (España). Red Latinoamericana de Estudios de Seguridad y Delincuencia Organizada (RELASEDOR). Miembro del Observatorio de Criminalidad Organizada Transnacional (OCOT). Universidad de Salamanca (España).

Email: daniel.sanso-rubert@usc.es

DOI: http://dx.doi.org/10.5209/rev_RUNI.2016.n41.52679
} 


\section{Aproximación criminológica a la delincuencia organizada y su identificación como amenaza estratégica ${ }^{2}$}

El fenómeno delictivo, lo mismo que cualquier otro hecho social, está estrechamente relacionado con las realidades que lo circundan. La delincuencia no se genera en "abstracto", sino que se materializa en un contexto espacio-temporal concreto. Tiene lugar en unas determinadas condiciones sociales, de desarrollo tecnológico, político y humano, que influyen decisivamente en la forma en cómo esa delincuencia se produce, en sus modos y maneras de manifestarse, en su cantidad, intensidad y en todas sus connotaciones y peculiaridades ${ }^{3}$.

La idea motriz que sustancia la peligrosidad intrínseca de la asociación criminal reside en la construcción de estructuras racionalmente orientadas a la planificación y comisión exitosa del delito, y al encubrimiento de sus miembros para evitar la persecución institucional. La organización criminal adquiere por tanto, cierta autonomía en relación a las personas individuales que contribuyen, mediante su aportación, a la consecución del objeto de esa estructura asociativa delictiva. En consecuencia, «organización» equivale a «estructura organizativa», que es denominador común de toda actividad desarrollada en el contexto de un ente colectivo.

Todo grupo u organización humana depende, entre otros elementos, de la creación, consolidación, ampliación, renovación y reconfiguración de un conjunto de vínculos sociales. Vínculos, que por una parte contactan entre sí a los individuos que forman parte del mismo. Pero que también implica, por otro lado, a personas que, a pesar de no estar formal o explícitamente afiliadas, mantienen relaciones frecuentes o significativas con la organización, bien con alguno de sus integrantes en concreto, bien con la totalidad del conjunto.

Desde este prisma, los grupos criminales son concebidos como redes sociales o entramados de relaciones interpersonales (familiares, de amistad, profesionales...). Visión, que resulta de gran ayuda para lograr comprender el funcionamiento real de la delincuencia organizada. No en vano, los contactos que mantienen y promueven los delincuentes organizados con otros individuos y colectivos son el medio a través del cual las organizaciones criminales afrontan toda oportunidad de negocio, a la par que amplían el número de colaboradores, afiliados y clientes ${ }^{4}$.

Destacar que sus capacidades de resistencia y resiliencia, se amplifican con el acceso al poder (económico, político o social). A su vez, la diversificación del portafolio de las actividades lícitas e ilícitas desarrolladas por las organizaciones criminales es tan variada, como fructífera. Cualquier actividad imaginable que resulte lucrativa será objeto de práctica, generando nuevos escenarios delictivos.

Resumiendo, sus actividades principales son aquellas que generan la provisión de bienes y servicios ilegales, ya sea la producción y tráfico de drogas, armas, menores, órganos, inmigrantes ilegales, materiales nucleares, el juego, la usura, la falsificación, la prostitución,

\footnotetext{
${ }^{2}$ Trabajo enmarcado en el Proyecto de Investigación DER2013-44228-R, financiado por el Ministerio de Economía y Hacienda de España, bajo el rubro "Delincuencia Organizada Transnacional: una amenaza para la seguridad de los Estados democráticos".

3 Sansó-Rubert Pascual, Daniel: "La internacionalización de la delincuencia organizada: análisis del fenómeno", UNISCI Discussion Papers, n. 9 (2005), pp. 43-62.

${ }^{4}$ Kleemans, Edward R. y de Poot, Christianne J.: "Criminal Careers in Organized Crime and Social Opportunity Structure”, European Journal of Criminology, Vol. 5, nº 1 (2008), pp. 69-98.
} 
la comercialización de bienes lícitos obtenidos subrepticiamente, especialmente los vehículos de lujo, animales y obras de arte, y la utilización de redes legales para actividades ilícitas como el lavado de capitales.

Resulta necesario clarificar que, con carácter general, no toda delincuencia organizada es internacional, ni que toda la internacional es organizada, puesto que múltiples grupos de delincuentes manifiestan notas características de organización pero, a pesar de ello, no tienen cabida bajo el título de delincuencia organizada, como la mera asociación temporal con fines delictivos (coautoría); y otros, que sí están categorizados como tal, no operan en la esfera internacional.

El que la delincuencia organizada haya alcanzado el estatus internacional no es un fenómeno nuevo. Supone la adaptación de figuras delictivas antiguas a las condiciones científicas, técnicas y sociales contemporáneas. Esta evolución se observa en cualquier época, pero parece que ha cobrado renovado brío particularmente en un siglo en el que el progreso técnico, de forma sobresaliente, se ha convertido en uno de los principales pilares de la civilización. La adaptación de la criminalidad a las nuevas condiciones de la vida moderna, ha propiciado de forma "natural" el salto a la internacionalización 5 .

Estratégicamente, el principal elemento de preocupación radica en la determinación de las organizaciones criminales a lograr su arraigo a niveles estructurales, principalmente políticos y económicos, aspirando a prevalecer como males sociales crónicos ${ }^{6}$.

\section{Nuevas tendencias de organización: surgimiento e implantación de las redes criminales}

La delincuencia organizada crece, muta y fruto de la transformación continua se perfecciona, consolidando estructuras organizativas cada vez más complejas. Estructuras, que posibilitan el que el fenómeno criminal organizado haya logrado un alcance integral: ha adquirido dimensiones globales (en lo geográfico), transnacionales (en lo étnico y cultural), multiformes (en su estructura $\mathrm{y}$ en los acuerdos que forja con sectores políticos y sociales) y pluriproductivas (en cuanto a la abundancia de bienes y servicios lícitos e ilícitos que transacciona $)^{7}$.

En el campo de la delincuencia organizada, no cabe hablar de organizaciones tipo, sino de tendencias tipológicas, habida cuenta de la gran diversidad de tipologías organizacionales que se pueden identificar bajo el rubro "criminalidad organizada". No en vano, al tratar de analizar las organizaciones criminales en su conjunto, aparece una amplísima variedad de tipos y formas que podrían configurarse como un continuo. En los extremos de éste se encuentran desde pequeñas asociaciones ligeramente organizadas, a través de vínculos débiles

\footnotetext{
5 Sansó-Rubert Pascual, Daniel: "Criminalidad organizada transnacional y seguridad internacional”, en Fernández Rodríguez, José Julio; Jordán, Javier y Sansó-Rubert Pascual, Daniel (eds.) (2008): Seguridad y Defensa hoy. Construyendo el futuro, Madrid, Plaza y Valdés, pp. 207-240.

${ }^{6}$ Sansó-Rubert Pascual, Daniel: “Globalización y delincuencia: el crimen organizado transnacional”, en Jordán, Javier y Pozo, Pilar (eds.) (2011): Más allá del Estado, Madrid: Plaza y Valdés, pp. 135-157. Sansó-Rubert Pascual, Daniel y Giménez-Salinas, Andrea: "Crimen organizado", en De La Corte, Luis y Blanco, José María (coords.) (2014): Seguridad nacional, amenazas y respuestas, Madrid, Editorial Lid, pp. 133-148.

${ }^{7}$ Tokatlian, Juan Gabriel: "La guerra antidrogas y el Comando Sur: Una combinación delicada", Foreign affairs: Latinoamérica, Vol. 10, no. 1 (2010), pp. 43-50.
} 
e inestables, hasta estructuras consolidadas y de notoria tradición criminógena. La escena conforma un variopinto conjunto de organizaciones cuya estructura, disciplina, normas internas, división de roles, actividades ilegales desarrolladas y, por ende, su peligrosidad, representan una pluralidad de combinaciones ${ }^{8}$. Esta diversidad constituye el principal impedimento para perfilar una definición universal, que consiga captar la esencia y las variables comunes de la totalidad de estas manifestaciones criminales 9 . De hecho, en función del grupo analizado, aspectos como la jerarquía, el número medio de integrantes, el papel de la mujer, la especialización de sus miembros o las relaciones intragrupales, por citar algunos elementos definitorios, son radicalmente opuestos ${ }^{10}$. Por lo que, para hacer un examen exhaustivo, habría que acudir al caso concreto.

Las estructuras que sirven de raigambre para organizar las actividades ilícitas manifiestan una alta plasticidad morfológica. Los esquemas piramidales de organización tradicionalmente asociados a la delincuencia organizada, aunque vigentes, tienden progresivamente a su transformación en tipologías más dinámicas (jerarquía regional, agrupación jerárquica, grupo central...), óptimas para desenvolverse en un escenario transnacional. De entre todas ellas, la organización en red $^{11}$ ha ido ganando predicamento, habida cuenta de las ventajas que confiere. La aplicación del análisis de redes sociales a la fenomenología criminal organizada, ha ganado una considerable atención desde los trabajos de Sparrow ${ }^{12}$. El análisis de redes ofrece muchos métodos que ayudan a ilustrar diversas metodologías de interacción entre organizaciones criminales, conformando estructuras criminales en red morfológicamente variables ${ }^{13}$.

El mínimo común denominador de una organización en red comprende un núcleo y una periferia, separadas por nodos intermedios que desempeñan la función de "interruptores", para salvaguardar el acceso a la cúpula (núcleo). Esta distribución refleja las asimetrías de poder, la influencia y el estado dentro de la red. En muchos casos, es habitual que las relaciones estén cimentadas a través de vínculos familiares o de parentesco (etnia, nacionalidad, familia, clan, identidad colectiva fraguada en el ámbito penitenciario...), pero no exclusivamente. Cada vez hay más organizaciones trasnacionales donde lo que prima es el prestigio y el reconocimiento profesional dentro del sector criminal (carreras criminales exitosas), como vehículo de adscripción.

A su vez, las organizaciones pueden estar compuestas por una variedad de células, entendidas como grupos de individuos que realizan tareas bien definidas dentro de la estructura, al objeto de desarrollar con éxito las actividades criminales. De entre todas, destacan por su grado de especialización de acuerdo a las funciones que desempeñan, las células ejecutoras (encargadas del control interno y la protección de la organización, de sus miembros y de sus intereses); células financieras (responsables del entramado económico-

\footnotetext{
${ }^{8}$ De La Corte, Luis. y Giménez-Salinas, Andrea (2010): Crimen.org. Evolución y claves de la delincuencia organizada, Barcelona, Ariel.

${ }^{9}$ Sansó-Rubert y Giménez-Salinas, op. cit. pp. 133-13.

${ }^{10}$ Sansó-Rubert, op. cit.

11 Arquilla, John y Ronfeldt, David (2003): Redes y guerra en red. El futuro del terrorismo, el crimen organizado y el activismo politico, Madrid, Alianza.

12 Sparrow, Malcolm. K.: "The application of network analysis to criminal intelligence: an assessment of the prospects", Social Networks n 13 (1991), pp. 251-274.

${ }^{13}$ von Lampe, Klaus y Johansen, Per Ole, (2004): "Organised crime and trust: on the conceptualization and empirical relevance of trust in the context of criminal networks", Global Crime Vol. 6, n 2 (2004), pp. 159-184; Bruinsma, Gerben y Bernasco, Wim, (2004): "Criminal groups and transnational illegal markets", Crime, Law and Social Change $\mathrm{n}^{\mathrm{o}} 41$ (2004), pp. 79-94; Klerks, Peter: "The network paradigm applied to criminal organizations", Connections Vol. 24, n³ (2001), pp. 53-65.
} 
financiero); células logísticas (asumen la adquisición de medios y capacidades, así como su mantenimiento, para el soporte de la actividad criminal); células de infiltración (su objetivo prioritario es introducirse en los estamentos encargados de enfrentar la delincuencia o en las áreas sensibles de los órganos centrales del Estado, en la Administración y en los organismos descentralizados o en empresas privadas, con el propósito de conseguir información protegida o de otra índole, atraer adeptos mediante diversos medios lícitos e ilícitos, y dañar, en la medida de lo posible, las capacidades del Estado de prevención y represión); células negociadoras (buscan acuerdos entre las diversas organizaciones criminales con la finalidad de solucionar disputas o ampliar y fortalecer alianzas); y, finalmente, la células operativas, que materializan las actividades delictivas ${ }^{14}$.

A su vez, existe la posibilidad, cada vez más extendida, del recurso a la externalización de determinados cometidos. Acudir a individuos (facilitadores) o estructuras ajenas a la organización (redes al servicio de redes) en determinadas fases del ciclo criminal, obedece a la especialización de la prestación ofrecida. Proveen de servicios financieros, económicos, técnicos, logísticos, contables, mercantiles y jurídicos, así como de una dilatada experiencia en el control del riesgo, permitiendo aumentar tanto la seguridad de las operaciones, como los beneficios. Existen incluso, organizaciones especializadas precisamente en la provisión de cobertura a la actividad ilícita: seguridad de las operaciones ${ }^{15}$, apoyo y soporte logístico (ocultación, transporte, almacenamiento...), operando como un eslabón más de la cadena delictiva organizada. Su relevancia, ha captado la atención institucional para su inclusión como objetivo prioritario a neutralizar, a los efectos de lograr atajar las manifestaciones de actividad criminal.

A pesar de las ventajas que ofrece la organización en red, no es óbice para olvidar que no son impermeables. La cuestión radica en identificar adecuadamente sus vulnerabilidades para su conveniente explotación.

La naturaleza de la estructura en red exige, que cualquier acción disruptiva, debe ser cuidadosamente planificada y ejecutada, si se pretende alcanzar éxito. Especialmente, la delimitación clara de los objetivos, cuestión que requiere de la herramienta inteligencia criminal. Resulta indispensable desarrollar una estrategia previa que determine si se pretende destruir la red, simplemente degradar su capacidad (logística, seguridad, transporte...), o neutralizar sus vínculos con la esfera de los negocios lícitos, la política o el apoyo social. Por ello, el estudio de las relacionales interpersonales, favorece la identificación, no sólo de quién es quién dentro de una organización, sino qué función desempeña, facilitando la selección de los objetivos más vulnerables o de interés, a la hora de planificar su desarticulación o infiltración. Frente a esta opción, los vínculos de confianza, más allá que los lazos étnicos, familiares o de cualquier otra naturaleza, dotan de una mayor resistencia a la organización, generando sinergias corporativas de seguridad.

De hecho, las organizaciones criminales invierten cada vez más en capacidades de seguridad y contrainteligencia (con sus respectivas vertientes ofensiva y defensiva). A efectos prácticos, interesa sobremanera identificar las iniciativas adoptadas por las organizaciones

\footnotetext{
${ }^{14}$ UNODC (2012): Compendio de casos de delincuencia organizada. Recopilación comentada de casos y experiencias adquiridas. en: https://www.unodc.org/documents/organizedcrime/SpanishDigest Final291012.pdf

${ }^{15}$ Gambetta, Diego (2007): La mafia siciliana. El negocio de la protección privada. México, Fondo de Cultura Económica.
} 
criminales para resguardar sus estructuras en aras de evitar la intrusión de elementos externos (fuerzas y cuerpos de seguridad u otras organizaciones competidoras), proteger a sus integrantes contra la acción de posibles amenazas o represalias, defender el desarrollo de sus actividades y preservar la información corporativa sensible.

La articulación de la seguridad corporativa implica:

- El chequeo y la acreditación de personas que tengan acceso a información sensible (catalogada formal o informalmente como clasificada).

- La creación y fomento de una cultura de seguridad corporativa entre quienes manejan este tipo de información, así como la sujeción a cumplir determinadas normas e instrucciones.

- La vigilancia de conductas anómalas de algún miembro.

- La identificación y vigilancia de organizaciones de interés, sean servicios de inteligencia u organizaciones criminales, procurando obtener conocimientos de cómo operan, la evaluación de los informadores y colaboradores, así como del producto (informaciones) por ellos suministrado y la realización de actividades de contrainformación e intoxicación informativa.

En suma, proteger las organizaciones de la infiltración hostil y la represión es un juego de suma cero, en el que el fracaso de la seguridad y la contrainteligencia, compromete gravemente las actividades y la estructura de la organización.

\section{Aproximación geopolítica en clave de inteligencia criminal: la difusión transnacional de la criminalidad organizada}

El tratamiento de la gran criminalidad organizada (entendida como aquellas manifestaciones criminales con capacidad de disputar al Estado el control territorial y social, así como el monopolio de la violencia), como sujeto geopolítico (actor armado no estatal), obedece a la necesidad de entender qué sucede en el escenario internacional vigente y cuál podría ser su evolución, en clave estratégica.

En general puede afirmarse que, la relación entre geografía y política, que dio lugar al nacimiento de la geopolítica ${ }^{16}$ como rama especial de estudio es una herramienta de máxima utilidad como elemento determinante para entender cómo las organizaciones criminales diseñan su transnacionalización, la articulación de las relaciones internacionales necesarias y derivadas de su expansión internacional, y las diversas fórmulas para dotarse del control de un marco territorial específico, todo ello de la forma más eficiente para sus intereses como organización.

Máxime, cuando las reivindicaciones geopolíticas paulatinamente se han ido situando en la confluencia de lo económico con lo político: el mundo actual se caracteriza por la

\footnotetext{
${ }^{16}$ Aunque originalmente el término geopolítica se debe al politólogo sueco Rudolf Kjellen, que lo formuló en 1899, suele atribuirse su paternidad al geógrafo alemán Friedrich Ratzel, en gran medida debido a que Kjellen, trabajó con las ideas de Ratzel (Ratzel, Friedrich (1898): The History of Mankind. New York, Macmillan and Co. Libro digitalizado: https://archive.org/ details/historyofmankind03ratzuoft30) y del maestro de éste, Karl Ritter. Parker, Geoffrey (1985): Western Geopolitical Thought in the Twentieth Century. London, Croom Helm.
} 
estrecha vinculación existente entre el poder político y el poder económico ${ }^{17}$, realidad en la que la criminalidad organizada opera con comodidad, ejemplificando uno de sus máximos exponentes; especialmente, cuando la geopolítica del siglo XXI se adentra en un espacio global donde gran parte del poder se ejerce fuera de una geografía física concreta, tal como sucede en el ciberespacio, donde la ciberdelincuencia goza de un amplio campo donde actuar con discrecionalidad, con elevados niveles de impunidad y plenamente inmersa en la esfera transnacional.

Las organizaciones criminales que operan a través de redes transnacionales se caracterizan por la capacidad de poder adaptar sus intereses y alianzas en todo momento: estar siempre dispuestas a cambiar de tácticas, a abandonar compromisos y lealtades. En esta línea argumental, la criminalidad organizada parece haber interiorizado con éxito los planteamientos del sociólogo Zygmunt Bauman ${ }^{18}$ cuando señala las reticencias y desafecto a establecer relaciones duraderas y a la fragilidad de los lazos inter partes, que parecen depender solamente de los beneficios que generan. La esfera comercial lo impregna todo, las relaciones humanas se miden en términos de coste y beneficio de «liquidez» ${ }^{19}$ en el estricto sentido financiero.

Tomando la definición que nos ofrece el profesor Bauman, nos encontramos en una nueva «modernidad liquida» ${ }^{20}$, una figura que trata de recoger este estado de cambio y transitoriedad permanente. Los sólidos conservan su forma y persisten en el tiempo: duran. Mientras que los líquidos son informes, adaptables, se transforman constantemente: fluyen. Una metáfora que parece apropiada para identificar un concepto de geopolítica, que es posible trasladar a las redes de criminalidad organizada y a la geopolítica criminal de la que se sirven, para una mejor comprensión de su exitosa proyección transnacional.

Consecuentemente, desentrañar la geopolítica criminal persigue comprender la lógica y ambiciones que motivan a aquellas personas responsables de la dirección de las organizaciones criminales (cúpulas). Identificar las motivaciones y estrategias que determinan el cómo y por qué se produce la expansión territorial de las organizaciones criminales, los factores coadyuvantes al respecto y los criterios que determinan el establecimiento de

\footnotetext{
${ }^{17}$ La geopolítica viene influida en lo sustancial por la geoeconomía, según los conceptos desarrollados por Edward Luttwak y por Pascal Lorot. Luttwak, Edward: "From Geopolitics to Geoeconomics: Logic of Conflict, Grammar of Commerce", The National Interest, $\mathrm{n}^{\circ} 20$ (January, 1990), pp. 17-23; Lorot, Pascal: "La géoeconomie, nouvelle grammaire des rivalités internationals", L'information géographique, Vol. 65, $\mathrm{n}^{\circ} 1$ (2001), pp. 43-52, en http://www.pezsee.fr/doc/ ingeo_0200_0093 2001_num_65_1_2733. Una adaptación del concepto de Lorot de geoeconomía extrapolado a la criminalidad organizada podría asimilarse como «el análisis de las estrategias de orden económico, adoptadas por las organizaciones criminales, conducentes a explotar favorablemente las economías nacionales o algunos de sus componentes, a adquirir el dominio de ciertas tecnologías claves, y/o a conquistar ciertos segmentos del mercado mundial relativos a la producción o comercialización de un producto o de una gama de productos sensibles, empleando estrategias lícitas e ilícitas, sobre los cuales, su posesión o su control confiere a los detentadores — criminalidad organizada transnacional— un elemento de poder o de proyección internacional y contribuye al reforzamiento de su potencial económico y social». La geoeconomía no se ajusta necesariamente a un territorio concreto, ni tiene una base territorial, en el sentido de proteger el bienestar de una población concreta. Se dirige, por el contrario, a la consecución de unos intereses políticos determinados mediante el uso de instrumentos económicos. Intereses que, en el contexto global, usan la economía y sus recursos, como elementos de poder o predominio. Olier, Eduardo $\left(2013,2^{\mathrm{a}}\right.$ edición): Geoeconomía. Las claves de la economía global, Madrid, Pearson-Prentice Hall.

${ }^{18}$ Bauman, Zygmunt (Poznań, Polonia, 1925), es un sociólogo, filósofo y ensayista polaco de origen judío. Desarrolló el concepto de la «modernidad líquida» junto con el también sociólogo Alain Touraine. Bauman recibió el Premio Príncipe de Asturias de Comunicación y Humanidades 2010.

${ }^{19}$ Bauman, Zygmunt (2004): Modernidad líquida. México D.F., Ed. Fondo de Cultura Económica.

${ }^{20}$ Ibid, pp. 62-65.
} 
relaciones entre las organizaciones y la naturaleza de las mismas, o justifican la confrontación $\operatorname{directa}^{21}$.

La geopolítica pretende ser sencillamente un método, una clave de lectura de acontecimientos: una herramienta de comprensión e interpretación de las relaciones internacionales. François Thual expone con claridad los tres principios fundamentales de la geopolítica moderna: todo fenómeno internacional es expresión de determinadas intenciones. La geopolítica investiga las intenciones reales de los actores internacionales, más allá de las apariencias y de los falsos pretextos. Una búsqueda de sus motivaciones ocultas. No existen leyes generales, sino factores que pueden combinarse. Thual defiende, que cada postura geopolítica responde o bien a una voluntad de materializar ciertas ambiciones, o bien a una necesidad de defenderse de alguna amenaza ${ }^{22}$. De igual forma, la geopolítica investiga las constantes y continuidad de los comportamientos e intenciones (perspectiva temporal). Finalmente, los comportamientos se inscriben en un espacio concreto. En definitiva, la función de esta disciplina consiste en captar las causas estructurales y permanentes, presentes en los fenómenos internacionales, e identificar las constantes y las repeticiones de la historia en sus relaciones con la geografía, con el fin de esclarecer los conflictos internacionales y las posturas de los actores implicados, atendiendo a la continuidad y trascendiendo las apariencias y lo inmediatamente visible, a favor de identificar la causa última. En su caso, la geopolítica criminal consistirá en aplicar los conocimientos de la disciplina a la criminalidad organizada para profundizaren su conocimiento, en lo que respecta a esta faceta concreta de actor armado no estatal.

La criminalidad organizada en su expansión territorial, tergiversa de facto los mapas oficiales, imponiendo su realidad geopolítica. Esta nueva geografía política mundial no estatal, condiciona la escena internacional actual: conlleva un reparto geográfico de áreas de dominio e influencia y el establecimiento de fronteras invisibles pero muy reales, emulando el concepto de "imperio invisible" de Pierre George, en su obra La géographie á la poursuite de $l^{\prime}$ histoire ${ }^{23}$. Cada organización tiene su propia demarcación territorial, de carácter infra y supranacional, al margen de los límites convencionales físicos y jurídicos oficialmente establecidos. Este orden territorial desafía las soberanías locales, estatales e internacionales.

Aparecen y desaparecen constantemente realidades geopolíticas criminales, cuyo modelo de expansión se fundamenta en el control territorial. Es posible identificar un núcleo territorial base, como punto de partida, donde surge y germina la organización delictiva. Este espacio territorial representa un enclave vital para su supervivencia, ya que han sido las características particulares del mismo las que han favorecido la eclosión y fortalecimiento de la estructura criminal, hasta el extremo de que ésta se haya fortalecido lo suficiente como para monopolizar el control del territorio y promover su progresiva expansión (la región de Nápoles, por ejemplo, en el supuesto de la Camorra, Calabria, si hablamos de la N'drangheta, Medellín y Cali en Colombia, o determinadas áreas geográficas de México, si hablamos de los principales cárteles de la droga, por citar ejemplos internacionalmente reconocidos). Territorio primigenio, que se consolida como baluarte de la organización criminal dominante y que, a su vez, le sirve de plataforma para su expansión, generalmente en fases sucesivas atendiendo a una diversidad de elementos ${ }^{24}$.

\footnotetext{
${ }^{21}$ Sansó-Rubert, Daniel: "Geopolítica criminal”, Revista Ábaco, monográfico: La venganza de la geopolítica, Vol. 3, no 85 (2015), pp. 62-75.

${ }^{22}$ Thual, François (1996): Méthodes de la géopolitique. París, Ellipses.

${ }^{23}$ George, Pierre (1992): La géographie á la poursuite de l'histoire, París, Armand Collin.

${ }^{24}$ Sansó-Rubert, op. cit. (2016).
} 
A priori, la hipótesis más extendida se inclina a favor del reconocimiento del delincuente profesional, integrado en una organización delictiva, como un homo economicus (Teoría criminológica de la elección racional). Un perfil profesionalizado, que ha escogido racionalmente el ejercicio de la delincuencia como modo de vida (livestyle) y asume su condición de experto y profesional de sus actividades.

Este planteamiento se inclina a favor de reconocer el fenómeno delictivo organizado como un comportamiento racional, pragmático y utilitarista, lo cual, en puridad, no sería del todo cierto. A pesar de ello, cabe presumir, a tenor de la información disponible contrastada que, de ordinario, los líderes de las organizaciones de delincuencia organizada son actores racionales auto-interesados ${ }^{25}$. Las organizaciones pueden ser consideradas como actores racionales, centrándose para este análisis exclusivamente en los grupos en su conjunto y en las decisiones tomadas exclusivamente por la dirección de las mismas. En este contexto analítico de partida, la racionalidad de los restantes miembros queda excluida, en tanto no son los que toman las decisiones dentro de la organización. Se supone que las decisiones que se adopten para interactuar con otros grupos, participar en ciertas actividades, o en términos generales, las decisiones que afectan a la organización en su conjunto, se tomarán al más alto nivel de liderazgo.

Desde esta perspectiva, la movilización de las organizaciones criminales obedecería a una estrategia de mercado y de acción expansionista, previamente planificada y diseñada, apoyada en el correspondiente análisis de riesgos ${ }^{26}$. Objetivo: el aprovechamiento de una serie de circunstancias identificadas como oportunidades para el lucro, ubicadas en diversos lugares por todo el mundo. Riesgos, que incluyen la confrontación con otras organizaciones por el control del territorio y de las actividades lícitas e ilícitas desarrolladas en él, cuando el pacto no es posible, o no interesa. Lo habitual es que el empleo de la violencia sea residual, porque no favorece los negocios (empleo pragmático de la violencia). El estallido de la violencia es síntoma de inestabilidad territorial (actualmente el caso mexicano). Comportamiento que suele darse en relación con un territorio controvertido, en disputa entre varias organizaciones para establecer el dominio de la plaza.

A pesar de su relevancia, el arraigo territorial no supone una limitación. No implica inmovilidad. Por ello, resulta igualmente factible identificar contextos emergentes, que originan el desplazamiento no intencional de las organizaciones criminales, motivado por factores de empuje (pull factors), sobrevenidos. Se trata en este supuesto, de una adaptación forzada a las circunstancias ambientales.

Dentro del conjunto de posibles factores a tener en consideración, aceptados por el conjunto de la doctrina especializada ${ }^{27}$, indistintamente válidos para explicar desplazamientos

\footnotetext{
${ }^{25}$ Shelley, Louise y Picarelli, John: "Methods and Motives: Exploring links between Transnational Organized Crime and International Terrorism ". Report for the US Department of Justice, funded by Grant 2003-IJ-CX1019. September 2005, en http://www.ncirs.gov/pdffiles1/nij/grants/211207.pdf

${ }^{26}$ Morselli, Carlo (2005): Contacts, Opportunities, and Criminal Enterprise, Toronto, University of Toronto Press.

${ }^{27}$ Varese, Federico (2013): Mafias on the Move: How Organized Crime Conquers New Territories, New Jersey, Princeton University Press; Morselli, Carlo (2009): Inside Criminal Networks, New York, Springer; Garzón, Juan Carlos; Rico, Daniel; Olinger, Marianna y Santamaría, Gema (2013): La Diáspora Criminal: la difusión transnacional del crimen organizado y cómo contener su expansión, Washington, DC, Woodrow Wilson International Center for Scholars; Gayraud, Jean François (2007): El G9 de las mafias en el mundo. Geopolítica del crimen organizado, Barcelona, Urano, colección «Tendencias»; Williams, Phill: “Redes criminales transnacionales”, en Arquilla, John y Ronfeldt, David (eds.) (2003): Redes y guerra en red. El futuro del terrorismo, el crimen organizado y el activismo político, Madrid, Alianza, pp. 61-97; Forgione, Francesco
} 
dentro del territorio nacional de un país, como cuando éstos son de carácter transnacional, destacan por su relevancia explicativa los siguientes:

\subsection{Búsqueda de recursos o de oportunidades de inversión (nuevos mercados)}

Dentro de las motivaciones para desplazarse al extranjero, aquella por antonomasia es la identificación de oportunidades de lucro (nichos de negocio fundados en base al cálculo de costos, riesgos y beneficios), estar dispuesto a su explotación y contar con la infraestructura, las capacidades y la logística para ello.

Las organizaciones criminales constantemente llevan a cabo tareas de recopilación de todo tipo de información, que les permita maximizar el éxito en las actividades que desenvuelven (lícitas e ilícitas), a los efectos de alcanzar la mayor competitividad posible que, a su vez, les procure mayores niveles de éxito y protección posibles ${ }^{28}$.

Otra motivación puede ser el acceso a nuevos mercados (en cooperación con otras organizaciones locales o en competencia) ${ }^{29}$, o la reorganización de las rutas de tránsito de los tráficos ilícitos, requiriendo presencia de la organización en determinadas áreas geográficas para su aseguramiento y apoyo logístico.

\subsection{Reinversión del producto obtenido ilícitamente en otros negocios}

Decisión motivada por la existencia de sistemas impositivos más favorables, el acceso a incentivos de desempeño proporcionados por los gobiernos, o por el deseo de operar en sistemas financieros más eficientes. También, como mecanismo de blanqueo de capitales para salvaguardar el patrimonio adquirido ilegalmente, lejos del alcance de cualquier jurisdicción que pudiera ponerlo en peligro (decomiso).

(2010): Mafia Export. Cómo la 'Ndrangheta, la Cosa Nostra y la Camorra han colonizado el mundo, Barcelona, Crónicas Anagrama; Varese, Federico: “General Introduction: What is Organized Crime?", en Varese, Federico (ed.) (2010): Organized Crime: Critical Concepts in Criminology, London, Routledge, pp. 1-33; Varese, Federico: "Mafia movements: a framework for understanding the mobility of mafia groups", Global Crime, Vol. $12, \mathrm{n}^{\mathrm{o}} .3$ (2011), pp. 218-231.

${ }^{28}$ A modo de ejemplo paradigmático, a finales de diciembre de 1991, los grupos criminales se reunieron en una dacha en la región montañosa de Viedentsovo, cerca de Moscú. Es probable que ésta sea una de las más importantes reuniones (sjodky) en la historia de la "mafia rusa", el número de "ladrones de ley" se aproximó a los treinta y llegaron hasta allí desde Georcia, Azerbayan, Armenia, Kiev, Odessa, Moscú, San Petersburgo y otros lugares tan alejados como Vladivostok, en la costa pacífica. La finalidad era acordar la distribución territorial y especializaciones delictivas, hecho que ya se estaba dando en Moscú, donde los barrios o áreas urbanas de influencia eran delimitados por las organizaciones criminales. A esta reunión le siguió la sjodka de Viedentsovo, en la que quedó patente el sentido de internacionalización que debían adquirir las acciones futuras de los grupos criminales más importantes. En esos momentos ya conocían que poco tiempo después Gorbachov liberalizaría las competencias en el comercio exterior. López, Julián: “Criminalidad organizada. La Mafia rusa y su estrategia de expansión”, Documento de Opinión 59/2015, Instituto Español de Estudios Estratégicos (IEEE), en http://www.ieee.es/Galerias/fichero/docs_opinion/2015/DIEEEO59-

2015 CriminalidadOrganizada_MafiaRusa_JLopezMunoz.pdf

${ }^{29}$ En la misma línea de ejemplo, en 1992 la organización Solntsevo entabló contacto con los cárteles de Cali y Medellín en Aruba, en una reunión que fue acordada por abogados de la mafia siciliana y la Camorra napolitana, la finalidad era la apertura de rutas de tráfico de cocaína a través de los Balcanes. En 1993 esta misma organización llevó a cabo una reunión en Miami para tratar su expansión por el extranjero y alianzas con otras organizaciones regionales y locales, en ella estuvieron presentes Boroda, Sergei Timofeyev, Victor Averin, Yuri Esin y Sergei Mikhailov. Decidieron iniciar sus operaciones de asentamiento en Italia, dado que ya mantenían contactos con organizaciones criminales locales. Ibid., pp. 12-13. 


\subsection{Aprovechamiento de los flujos migratorios y de las políticas de deportación masiva}

La expansión criminal está estrechamente ligada a la historia y geografía de las oleadas migratorias. El desplazamiento de una comunidad y su asentamiento en otro lugar conforma el sustrato mínimo indispensable para el desarrollo de la actividad criminal como producto de importación ${ }^{30}$. Ciertamente, el mero traslado de elementos del crimen organizado a un nuevo territorio no es motivo suficiente para que emerjan estructuras de delincuencia organizada. Sin embargo, existe constancia de que las organizaciones criminales se benefician proactivamente de diversas maneras de los movimientos migratorios. Principalmente para la obtención de beneficios económicos mediante la panoplia delictiva que comprende la inmigración ilegal. Además, a través de su instrumentalización, logran solaparse en las comunidades asentadas en los países de acogida en busca de protección y zonas de influencia, explotando relaciones étnicas, familiares y clientelares ${ }^{31}$. De este modo, el mapa histórico de las migraciones mundiales y las diásporas encubre, en mayor o menor medida, el de la difusión de la criminalidad organizada.

En relación con las deportaciones masivas, el caso más paradigmático y ejemplarizante ha sido protagonizado por Estados Unidos en relación a la extradición masiva de miembros de pandillas originarias de Los Ángeles, a sus países originarios del Triángulo Norte (Honduras, Guatemala y El Salvador). Fruto de la cual, estos países recibieron directamente el influjo de la subcultura delictiva de bandas, sin contar con los medios institucionales adecuados para su gestión y control $^{32}$. Resultado, la eclosión descontrolada y fortalecimiento del fenómeno de las maras, que representa a día de hoy uno de los principales problemas de seguridad en la región Centroamericana, con tasas de homicidios desorbitadas en comparación con áreas de conflicto armado como Afganistán, Somalia o Líbano y que refleja un perfil de compleja resolución.

\subsection{Vacío represivo}

Obedece a diferentes causas. A una voluntad política corrupta en connivencia con la criminalidad (nexo político criminal) ${ }^{33}$, a una situación de impotencia generada por la debilidad institucional o simplemente, por distracción ante otros desafíos de seguridad como el terrorismo, que desplace al resto de fenómenos monopolizando todo el esfuerzo y los recursos, siempre limitados, de los organismos y agencias de seguridad.

Un contexto nefasto lo conforman las alianzas entre políticos, organizaciones delictivas y el aparato de seguridad estatal. Dicha connivencia genera en la práctica, bien respuestas tibias de los gobiernos, bien directamente la omisión de respuesta pública (catarsis institucional). Su manifestación más dañina se plasma cuando el Estado se transforma en refugio criminal, imperando el fomento de obstáculos para la cooperación internacional destinada a su erradicación ${ }^{34}$.

\footnotetext{
${ }^{30}$ Sansó-Rubert (2008): op. cit.

${ }^{31}$ Savona, Ernesto Ugo; di Nicola, Adrea y da Col, Giovanni: "Dynamics of migration and crime in Europe: new patterns of an old nexus", Transcrime, Working Paper no 8 (1997), Trento, Universidad de Trento.

${ }^{32}$ Garzón, Juan Carlos (2012): La rebelión de las redes criminales: el crimen organizado en América Latina y las fuerzas que lo modifican, Washington, D.C., Woodrow Wilson International Center for Scholars.

33 Godson, Roy (ed) (2004): Menace to Society: Political-criminal Colllaboration Around the World, Transaction publishers, New Brunswick (USA) y London (UK).

34 Berdal, Mats y Serrano, Mónica (comp.) (2002): Crimen transnacional organizado y seguridad
} internacional. Cambio y continuidad, México D.F., Fondo de Cultura Económica. 
En la práctica, los grupos que controlan estos espacios ingobernados ("santuarios criminales"), se convierten en socios estratégicos para las organizaciones de delincuencia organizada transnacional ${ }^{35}$.

\subsection{Exilio fruto de la presión política y policial o por la confrontación entre organizaciones por áreas de influencia (geográficas y mercados)}

El exilio puede deberse primordialmente a dos causas determinantes. Por una parte, la puesta en práctica de políticas gubernamentales de represión. De otra, la propia competencia criminal, que puede degenerar en enfrentamientos violentos con facciones $u$ organizaciones vencedoras y vencidas (disputas por el control de áreas geoestratégicas, mercados, como por los corredores y rutas para tráficos ilícitos, pasos fronterizos, nudos de comunicaciones, puertos...). La reubicación en otros países obedece a una necesidad de supervivencia. En definitiva, el exilio como escapatoria de la prisión o de la muerte.

En cuanto a la repercusión de la presión política y policial que adoptan los gobiernos dentro de sus fronteras, la delincuencia, en aras de una mayor y más eficiente autoprotección, ha optado por asentarse en aquellos países que presentan características más favorables, en contraposición con sus naciones de origen. Son candidatos predilectos los Estados dotados de ordenamientos jurídicos laxos, excesivamente garantistas si se prefiere, con leyes de extranjería permeables y políticas criminales infradesarrolladas o desfasadas, que les permiten operar al amparo de los beneficios reportados por el marco de legalidad descrito ${ }^{36}$.

Los efectos de la dispersión forzada son de naturaleza traslativa; una propagación involuntaria debido a que la problemática no se resuelve, sino se desplaza hacia otra ubicación geográfica (efecto globo). Las organizaciones desplazadas, lejos de abandonar sus prácticas criminales, las exportan. Igualmente, fruto de esta presión institucional, se ha producido la fragmentación de las organizaciones criminales, favoreciendo la emergencia de una nueva generación de organizaciones más reducidas y dinámicas, que compiten ferozmente por el dominio del territorio que, con anterioridad, dominaba una única estructura criminal, disparando los índices de violencia (México y Colombia representan los ejemplos por antonomasia, a raíz de la eclosión de nuevos cárteles y de las denominadas bandas criminales -BACRIM-, en sustitución de los cárteles tradicionales y las organizaciones paramilitares).

\subsection{Existencia de una cultura materialista y consumista}

La delincuencia organizada es una modalidad de crimen, que se inserta en una matriz en la que la sociedad es al mismo tiempo víctima y beneficiaria de los bienes y servicios de los que la provee ${ }^{37}$. En consecuencia, el escenario en el que se desarrolla el crimen organizado hoy es el de una cultura funcional a su expansión.

Esta realidad despierta encendidos debates sociales y de política criminal, en relación a la despenalización del consumo de determinadas sustancias catalogadas actualmente como

\footnotetext{
35 Naím, Moisés (2006): Ilícito. Como traficantes, contrabandistas y piratas están cambiando el mundo, Barcelona, Debate.

${ }^{36}$ Sansó-Rubert (2008): op. cit.

${ }^{37}$ Rotman, Edgardo: "The globalization of criminal violence», Cornell Journal of Law and Public Policy, Vol. 10, $\mathrm{n}^{\mathrm{o}} 1$ (2000), pp. 1-45; Naylor, Robin Thomas (2000): Wages of crime: black markets, illegal finance and underworld economy, Ithaca, Cornell University Press.
} 
drogas en multitud de legislaciones (hachís y cannabis, principalmente, además de otras tradicionales de consumo más residual, como el peyote o la hoja de coca, vinculadas a ritos animistas ancestrales o con una fuerte carga cultural). Una reproducción actualizada del debate acerca de las políticas prohibicionistas del alcohol de principios del siglo XX, que se dirimió con la despenalización de su consumo.

Con independencia de los argumentos a favor y en contra, que trascienden el objeto de este análisis, ciertamente el afán consumista al que la sociedad contribuye, en mayor o menor medida, alimenta la fenomenología criminal organizada. Siempre que exista una demanda rentable (artículos falsificados, drogas, sexo, vehículos de lujo, autopartes, piratería informática o audiovisual...), habrá alguien dispuesto a satisfacerla, con independencia de que los medios sean lícitos o no.

\subsection{Impacto del crimen organizado sobre la autoridad estatal: Estados débiles y criminalmente cautivos (efecto corrupción)}

Obviamente todos los Estados son vulnerables a la infiltración criminal, pero existe una diferencia cualitativa entre Estados autónomos (relativamente efectivos) y Estados débiles o impotentes $^{38}$. Los Estados con una falta de consolidación del sistema democrático y un deficiente desarrollo de sus instituciones públicas configuran un terreno propicio para la actividad de los grupos criminales ${ }^{39}$.

La ausencia de monopolio estatal sobre los recursos coercitivos y políticos, abona la semilla para el surgimiento y expansión de la criminalidad organizada. La abdicación del poder estatal total o parcialmente es condición sine qua non de la exitosa empresa criminal. Cuando los Estados se descomponen (vacío de poder), la delincuencia organizada toma la iniciativa.

Otro ámbito sobre el cual incide perniciosamente el crimen organizado corresponde a la cultura política de un determinado país. Es decir, el conjunto de valores y actitudes que informan la acción política de los ciudadanos. Afecta sensiblemente al entorno social de las democracias, distorsionando las líneas que separan lo legal de lo ilegal, generando lealtades alternativas al Estado y provocando cambios en la opinión pública, que afectan negativamente al funcionamiento del sistema ${ }^{40}$.

La tendencia apunta a que los dirigentes de estas organizaciones criminales traducen la riqueza acumulada en demandas políticas, sociales y económicas. Aspiran a convertirse en miembros de la «élite social y política», destinando parte de su poder económico a la obtención de legitimidad social. Así, se termina produciendo una asimilación social de los dirigentes criminales, entremezclándose con las esferas de poder. Valiéndose de ardides

\footnotetext{
${ }^{38}$ Casanovas, Oriol: "Los Estados Fracasados", en García, Caterina y Rodrigo, Ángel J. (eds.) (2008): $L a$ seguridad compartida. Nuevos desafios, amenazas y conflictos armados, Barcelona/ Madrid: Universitat Pompeu Fabra/Tecnos, pp. 83-89.

39 Sansó-Rubert Pascual, Daniel: "Impacto social del fenómeno criminal organizado: déficit constitucional, deslegitimación estatal, corrupción, radicalización y crisis de Gobernanza”, en Bañón i Martínez, Rafael y Tamboleo García, Rubén (eds.) (2013): Gestión de la escasez: participación, territorios y estado del bienestar. Experiencias de democracia y participación, Madrid, GOGEP Complutense, pp. 297-305.

40 Sansó-Rubert Pascual, Daniel: “¿Representa la criminalidad organizada una amenaza para la democracia?: Aproximación a la génesis antidemocrática del fenómeno delictivo organizado”, en Bañón i Martínez, Rafael y Tamboleo García, Rubén (coord.) (2014): La modernización de la política y la innovación participativa, Madrid, GOGEP Complutense, pp. 221-240.
} 
populistas, pueden igualmente manipular los afectos de poblaciones enteras, generalmente caracterizadas por el retraso económico y las desigualdades sociales, posicionándolas frente al Gobierno central o frente a las instituciones supranacionales.

El acceso al poder en definitiva es una salvaguarda de su estatus. Éste se cristaliza en el carácter políticamente pragmático de la criminalidad organizada. Instrumentalizará convenientemente su apoyo a favor de aquellas iniciativas políticas que beneficien sus propios intereses.

El sistema electoral tampoco escapa a su esfera de influencia. De facto, en no pocas ocasiones recurren a la manipulación del proceso electivo mediante la postulación de candidatos propios, hacia los que canalizan ingentes recursos económicos e informativos procedentes de sus negocios ilícitos o, en regiones donde el clientelismo es una característica endémica, pueden poner al servicio del candidato «predilecto» el electorado indispensable para la victoria. Su poder económico les permite, llegado el caso, subordinar a partidos políticos preexistentes o crear los suyos propios, para así tener un mejor control sobre toda la estructura de decisiones en las instituciones de representación política. Con ello, contribuyen a la deformación y el descrédito de la democracia, reemplazando la auténtica representatividad electa por la mercantilización instrumental de candidatos y electores ${ }^{41}$.

\subsection{Delincuencia organizada, economía y globalización}

La delincuencia organizada no es una rareza original surgida al hilo de la globalización. No ha irrumpido repentinamente en la historia de la criminalidad (nihil nove sub sole), sino que, por el contrario, ha evolucionado de forma paralela a la sociedad, hasta presentarse en los tiempos actuales con una faz innovada respecto de las formas tradicionales.

En lo que respecta a la conjunción criminalidad organizada, economía y globalización, la actividad delictiva genera inestabilidad financiera, a la par que distorsiones e ineficacias en los mercados. Provoca disfunciones estructurales en la economía, que afectan negativamente a los ciudadanos y a la estabilidad del sistema democrático.

La liberalización económica ha procurado novedosas expectativas para los que están involucrados en mercados penalizados. Algunas de las mismas iniciativas diseñadas para estimular y facilitar el intercambio económico legal (liberalización comercial y financiera, privatización, desregularización del transporte), benefician el intercambio económico ilegal y que en muchas regiones del mundo, la economía criminalizada constituya una fuente decisiva, tanto de ingresos como de empleo (economías criminales altamente competitivas como acontece en China respecto de la falsificación de marcas). Con esto no se está sugiriendo que la globalización, en su vertiente económica, sea la causa fundamental de la delincuencia organizada transnacional, pero sí representa una variable trascendental para explicar su proliferación.

En conjunto, las repercusiones de la inmersión del crimen organizado en el ámbito de la economía son inflación, una distribución ineficiente de rentas, la disolución del libre mercado y la regulación económica estatal, pérdidas substanciales de productividad, una visión utilitarista de la inversión contraproducente con el crecimiento económico prolongado $\mathrm{y}$, en ocasiones, sobrevaluación monetaria. En lo que se refiere al sistema financiero en particular, la volatilidad de los capitales en manos de los grupos criminales dificulta las

\footnotetext{
${ }^{41}$ Sansó-Rubert (2014): op. cit.
} 
acciones correctas en materia de política económica y provoca inestabilidad en las instituciones bancarias y en el mercado del dinero en general, lo cual puede desembocar en una crisis económica profunda.

En cuanto a los desplazamientos de las organizaciones criminales se refiere (en un mundo globalizado), algunos autores establecen diferentes categorías en función del modo en que éstos se producen ${ }^{42}$. Concretamente, identifican como expansión, el desplazamiento caracterizado por la presencia en nuevos territorios pero adoptando un perfil bajo. Autolimitando las capacidades de actuación, con la finalidad de permanecer desapercibidos. La trasplantación, por el contrario, se corresponde con un desplazamiento parcial. Las organizaciones sólo reproducen parcialmente su estructura enfocándose generalmente en tres líneas operativas: tráficos ilícitos y alianzas para la distribución local al por menor, lavado de activos y búsqueda de refugio para los integrantes de las cúpulas. Esta opción se reproduce habitualmente en los principales centros urbanos de aquellos países que representan un interés estratégico para la criminalidad organizada (Madrid, ejemplifica esta modalidad en relación al tráfico de cocaína). Finalmente, una tercera categoría sería la representación criminal, que consiste en el desplazamiento temporal de miembros de la organización al territorio de otra con la que se mantiene algún tipo de relación comercial. Mecanismo, que opera como garantía de cumplimiento y de no confrontación, en las transacciones ilegales en las que predomina la desconfianza. A su vez, los miembros desplazados, actuarían como supervisores de los desempeños de la contraparte para la que sirven de garantía, asegurándose del correcto desempeño de los parámetros acordados.

Cabría, a mi juicio, incorporar una cuarta categoría para recoger aquellas situaciones de conquista territorial. Cuando la expansión es definitiva y el establecimiento en el territorio pleno. Se produce con la intención de su incorporación al espacio bajo el control de la organización criminal: el asentamiento.

Todas estas categorías explicativas, que no son únicas ni excluyentes, resultan de utilidad para la comprensión de la movilización del crimen organizado. El resultado de su distribución geográfica mundial es muy desigual, dependiendo tanto de las condiciones regionales o locales (vacío de poder político e ideológico, una historia previa de delincuencia en mayor o menor medida organizada, condiciones geográficas expresas como áreas de cultivo o rutas de tránsito de tráficos ilícitos, pauperización de la población, debilidad institucional del Estado...), como del tipo de actividad criminal de la que se trate. Adoptará diversas formas de propagación acorde con sus objetivos, la capacidad de respuesta institucional en los territorios o ciudades en donde incursiona, y en función de las relaciones que establezca con las organizaciones delictivas locales ${ }^{43}$.

Como acontece en cualquier otro sector de negocios, el acceso al capital relacional, sumado a la confianza, resultan de vital importancia para el desarrollo de las actividades delictivas. Máxime, en un entorno donde cualquier alteración, diferencia de términos en la prestación del servicio o abastecimiento del producto o incumplimiento respecto de lo pactado, no se dirime precisamente en los juzgados. La clave teórica del éxito estriba en generar relaciones interpersonales fiables, sólidas y estables: alianzas estratégicas. Además, la identificación de oportunidades de lucro (nichos de negocio fundados en base al cálculo de costos, riesgos y beneficios), implica estar dispuesto a su explotación y contar con la infraestructura, las capacidades y la logística para ello.

\footnotetext{
${ }^{42}$ Varese (2013): op. cit.; Garzón (2012): op. cit.

${ }^{43}$ Varese (2013): op. cit.
} 
Sea como fuere, lo cierto es que los grupos de criminalidad organizada representan una realidad incuestionable. Se han desarrollado en Asia, América Latina, África, Europa y Estados Unidos; ninguna región del mundo y ningún sistema político ha impedido su surgimiento o logrado un éxito rotundo en su eliminación. Esta imagen refuerza la idea de que la criminalidad organizada fructifica explotando las ventanas de oportunidad abiertas, no solo en los países más desfavorecidos del planeta, prosperando en un estado de caos y conflicto constante (agujeros negros geopolíticos) ${ }^{44}$, sino que por igual, accede al primer mundo en busca de escenarios y mercados estables en los que implantarse y desarrollar sus actividades lucrativas. Cualquier intento de explicar la situación en cualquier zona inestable o estable del mundo, exige entender el papel de las redes criminales en la región, su organización, sus estrategias, sus vínculos internacionales e intereses económicos. En congruencia, internacionalmente habría que prestar especial atención a estos espacios geográficos favorables al surgimiento de manifestaciones ventajosas para la criminalidad organizada, cuyo seguimiento permitiría identificar con antelación las posibles incursiones oportunistas de redes criminales.

Llegados a este punto, se abre para la geopolítica y la inteligencia criminal un interesante ámbito de estudio, brevemente esbozado en las reflexiones compartidas en estas líneas. Resumidamente y a modo de colofón, la conjunción de ambas disciplinas aporta explicaciones sobre la existencia de dicho fenómeno y establece posibles evoluciones o tendencias, definiendo escenarios posibles y probables. Además, define las alternativas estratégicas viables para reorientar la situación en el sentido más favorable para su erradicación y control. De la misma forma, posibilita conocer y analizar la distribución geográfica de la actividad delictiva, la concentración territorial de las organizaciones criminales (densidad criminal), el surgimiento de nuevos nichos de mercado ilícitos, la identificación de las estrategias puestas en práctica por las estructuras delictivas, así como la detección del ascenso y caída de las organizaciones criminales, en virtud de sus fortalezas y debilidades. Todo un reto académico por abordar, ya que lo cierto es que aún disponemos sólo de un conocimiento limitado sobre cómo se articulan los procesos de difusión de la delincuencia organizada. Profundizar en el estudio para la comprensión de la movilidad criminal representa un reto para los investigadores.

\section{Radiografía del entramado relacional de las organizaciones criminales}

De igual forma, a pesar del conocimiento adquirido ${ }^{45}$, aún son muchos los vacíos de información que deben ser subsanados en este ámbito. Las conexiones que diariamente se

\footnotetext{
${ }^{44}$ Naím, op. cit.

${ }^{45}$ Edwards, Adam y Gill, Peter: "The politics of transnational organised crime: discourse reflexivity and the narration of threat', British Journal of Politics and International Relations, Vol. 4, $\mathrm{n}^{\circ} 2$ (2002), pp. 245-270; Williams, Phill: “Cooperación entre las organizaciones criminales”, en Berdal, Mats y Serrano, Mónica (comp.) (2002): Crimen transnacional organizado y seguridad internacional. Cambio y continuidad, México D.F., Fondo de Cultura Económica; Woodiwiss, Michael:"Transnational Organized Crime: The Strange Career of an American Concept", en Beare, Margaret E. (ed.) (2003): Critical Reflections on Transnational Organized Crime Money Laundering and Corruption, University of Toronto Press, Toronto, ONT, pp. 3-34. Ruggiero, Vincenzo: "Transnational crime: Official and alternative fears", International Journal of the Sociology of Law, Vol. 28, n 3 (2000), pp. 187-199; Sheptycki, James: “Against Transnational Organized Crime”, en Beare, Margaret E. (ed.) (2003): Critical Reflections on Transnational Organized Crime Money Laundering and Corruption, University of Toronto Press, Toronto, ONT, pp. 120-144.
} 
entablan entre organizaciones criminales, permanecen opacas. A pesar de ello, conocedores del pragmatismo adaptativo de las organizaciones delictivas, tendentes a incorporar a su acervo particular todo aquello que funcionalmente haya demostrado ser exitoso en su aplicación, cabe plantearse que se haya producido la extrapolación de los sistemas de interrelación del sector empresarial al criminal, con los correspondientes matices.

Dinámica evolutiva, actualmente marcada por una etapa de transformaciones importantes, que definirán el tipo de criminalidad organizada que deberemos enfrentar en años venideros. A grandes rasgos, una breve radiografía de la escena criminal internacional trasluce una riqueza tipológica multinacional, pluriétnica, multiorganizacional y multiactividad. La delincuencia organizada no conforma un grupo monolítico sino que, más bien, presenta un panorama poliédrico, complejo y multidimensional.

Para mejorar nuestra comprensión de la naturaleza de los vínculos de cooperación entre las organizaciones criminales, es recomendable recurrir a la literatura de administración y dirección empresarial. Analizar las formas en que las empresas cooperan y compiten y, en particular, la manera en que se articulan y consolidan las alianzas estratégicas.

Cuadro 1. Tipología de relaciones cooperativas de la delincuencia organizada

\begin{tabular}{|c|c|c|c|}
\hline $\begin{array}{l}\text { Tipo de } \\
\text { relación }\end{array}$ & Forma de cooperación & $\begin{array}{l}\text { Características } \\
\text { cooperación }\end{array}$ & Beneficios de la cooperación \\
\hline $\begin{array}{l}\text { Alianza } \\
\text { estratégica }\end{array}$ & $\begin{array}{l}\text { Nexos operativos } \\
\text { Franquicia }\end{array}$ & $\begin{array}{l}\text { A Largo plazo } \\
\text { Alto nivel de confianza }\end{array}$ & $\begin{array}{l}\text { Cooptar al adversario } \\
\text { potencial } \\
\text { Sinergias que facilitan la } \\
\text { entrada al mercado }\end{array}$ \\
\hline $\begin{array}{l}\text { Alianza } \\
\text { táctica }\end{array}$ & $\begin{array}{l}\text { Licencia } \\
\text { Conexiones operativas }\end{array}$ & $\begin{array}{l}\text { Pericia Complementaria } \\
\text { Corto plazo } \\
\text { Desarrollo de un nivel } \\
\text { moderado de confianza }\end{array}$ & $\begin{array}{l}\text { Explotar nexos locales- } \\
\text { globales } \\
\text { Sinergias que facilitan la } \\
\text { entrada al mercado }\end{array}$ \\
\hline $\begin{array}{l}\text { Contrato y } \\
\text { servicio } \\
\text { Intercambio }\end{array}$ & $\begin{array}{l}\text { Relacionadas con } \\
\text { tareas especializadas } \\
\text { Acuerdos de trueque }\end{array}$ & $\begin{array}{l}\text { Relación de tipo empleador } \\
\text { A corto o a largo plazo } \\
\text { Limitada al intercambio de } \\
\text { productos }\end{array}$ & $\begin{array}{l}\text { Uso de habilidades } \\
\text { especializadas } \\
\text { Extender gama de productos } \\
\text { y desarrollar nuevos } \\
\text { mercados }\end{array}$ \\
\hline $\begin{array}{l}\text { Proveedor } \\
\text { regular } \\
\text { Proveedor a } \\
\text { corto plazo }\end{array}$ & $\begin{array}{l}\text { Proveedor-cliente } \\
\text { Al por mayor y al } \\
\text { menudeo }\end{array}$ & $\begin{array}{l}\text { Grado de confianza y } \\
\text { pronóstico } \\
\text { Expeditiva e instrumental }\end{array}$ & $\begin{array}{l}\text { Altamente eficiente y } \\
\text { adaptable } \\
\text { Proporciona soluciones } \\
\text { interinas para satisfacer } \\
\text { demandas del mercado }\end{array}$ \\
\hline
\end{tabular}

*Información extraída de Williams, Phill: “Cooperación entre las organizaciones criminales”, en Berdal, Mats y Serrano, Mónica (comp.) (2002): Crimen transnacional organizado y seguridad internacional. Cambio y continuidad, México D.F., Fondo de Cultura Económica.

La gama de tipologías de cooperación es muy variada. Pueden adoptar multiplicidad de formas a lo largo de un espectro que abarca desde alianzas estratégicas en un extremo, hasta relaciones de proveedor a corto plazo. Los vínculos de negocio giran en torno 
a la cadena mundial de productos (lícitos e ilícitos). Cadena que comprende desde la materia prima hasta el producto final (ciclo criminal). Tales enlaces forman parte integral de la operativa cotidiana de las actividades criminales.

Consecuentemente, las ventajas de la cooperación entre organizaciones criminales reside en:

- Permite superar las limitaciones organizacionales propias (logísticas, protección,...)

- Mejora la posición competitiva en el mercado y facilita la neutralización de los principales competidores

- Maximización del lucro obtenible (aumento de cuotas de mercado)

- Acceso a nuevos mercados (alianza vs. competencia)

- Reducción de riesgos y minimización de inversiones frente a la imprevisibilidad del mercado (riesgo de incautación, pérdida de mercancía, desarticulación policial de células de las organizaciones...)

- Aumento de la base de los recursos disponibles, ya sea en términos de capital, tecnología, capital relacional, acceso a nuevos mercados... .

- Incremento de las oportunidades para el aprendizaje organizacional a través del intercambio de información y conocimientos entre los socios (desarrollo de confianza mutua)

- Favorece la especialización y la división del trabajo en relación con los proveedores

- Compartir entre los socios los riesgos y los costes financieros y de operación

- Fragmentación del ciclo criminal en función de las capacidades y la especialización de las organizaciones (protección, transporte, almacenamiento, distribución...)

Los incentivos para la cooperación entre organizaciones criminales están al alza, dando como resultado una «cadena global de redes criminales, que serán tan difíciles de combatir como lo son de rastrear» ${ }^{46}$. La violencia, desde una perspectiva racional economicista, perjudica los negocios. No sólo desgasta a las organizaciones criminales (pérdidas fruto del enfrentamiento), sino que las distrae de la actividad principal: obtener beneficios (lucro cesante). A ello hay que sumar, que incrementa su visibilidad al captar la atención de los medios de comunicación y por ende, su exposición a la actuación de la seguridad estatal. No obstante, a pesar de la suma de inconvenientes, llegado el caso, el recurso a la violencia representa uno de los principales instrumentos de acción de la delincuencia organizada.

Explicar por qué unas alianzas alcanzan éxito y otras fracasan resulta harto complejo, habida cuenta de la multitud de factores y variables intervinientes. El punto de partida para considerar esta cuestión radica en asimilar que la piedra angular para cualquier relación en el ámbito de la delincuencia organizada es la necesidad mutua y la búsqueda de beneficio. Necesidad, en tanto la organización no dispone de los medios pertinentes para asumir esa fracción del ciclo criminal. Cada organización aporta algo que la otra necesita y no dispone. Y, la obtención de lucro, que impulsa a la asunción de riesgos (sin riesgo, no hay ganancia). Lógicamente, si además del mutuo reconocimiento existe una relación de respeto-confianza, las probabilidades de éxito presentes y futuras incrementan. Sin embargo, incluso cuando la selección del aliado es adecuada, esto no es garantía alguna de alcanzar el éxito.

\footnotetext{
${ }^{46}$ Williams (2002): op. cit.
} 
Establecer relaciones fructíferas duraderas en la esfera criminal encierra una pluralidad de dificultades. Principalmente, no existen mecanismos formales para exigir el cumplimiento del acuerdo alcanzado. No hay estancias de reclamación formal. No se dispone de una regulación expresa que determine qué sucede cuando acontecen incumplimientos imprevistos por causas sobrevenidas o intencionadamente. De hecho, subyace el sustrato base para que puedan surgir desavenencias con demasiada facilidad. Los actores implicados transitan de ordinario por el mundo de la ilegalidad, por lo que se caracterizan por el desapego al respeto a las normas y a los derechos del prójimo, características de las subculturas delictivas. Idiosincrasia, además, donde la violencia intragrupal y extragrupal, es un recurso habitual para mantener la cohesión de las organizaciones y como fórmula para dirimir controversias.

A lo expuesto hay que sumar, el que puedan darse desiguales ganancias resultantes, ganancias que no cubren las expectativas previstas o pactadas (desproporcionales), que se desvirtúen equilibrios de influencia pactados en determinados espacios geográficos o institucionales, hacerse con la cartera de clientes de la contraparte y prescindir de su implicación en el negocio... toda una amplia gama de posibles escenarios generadores de disconformidad. En definitiva, los vínculos entre organizaciones criminales están continuamente sujetos a escrutinio en virtud de su inestabilidad.

El análisis esbozado, no pretende ofrecer una explicación omnicomprensiva acerca de la tipología de relaciones posibles en el ámbito criminal organizado. La intención persigue, simplemente, aportar una reflexión que, sumadas a otros trabajos académicos, favorezca la apertura de líneas de investigación sobre la naturaleza de las alianzas entre las organizaciones criminales. Resulta crucial ahondar más allá de las generalizaciones acerca de una pretendida "Pax Mafiosa" (el reparto del mundo en feudos criminales) ${ }^{47}$, y proporcionar un marco conceptual de análisis para su estudio y comprensión.

Es necesario tener igualmente en consideración, el hecho de que las organizaciones criminales establezcan vínculos de diversa naturaleza con gobiernos y con organizaciones terroristas para la satisfacción de intereses mutuos ${ }^{48}$. Circunstancia, que dificulta aún más, el análisis relacional desplegado por la criminalidad organizada.

El resultado, networks criminales compuestas por sujetos y entidades pertenecientes a ámbitos diversos -la política, el mundo empresarial, el sistema financiero, el ámbito de la delincuencia organizada- cuyas sinergias e intereses compartidos, dan vida a potentes conglomerados organizados capaces de condicionar áreas enteras de la vida pública y de controlar espacios geográficos y vastos sectores de determinados mercados legales e ilegales.

\section{5. Éxito o fracaso futuro en la lucha contra el fenómeno criminal organizado: El acceso a los sistemas criminales como reto emergente de la inteligencia criminal}

El debate sobre el desarrollo de la inteligencia aplicada al análisis de la fenomenología criminal organizada, más allá de las disquisiciones conceptuales que deberán ser superadas

\footnotetext{
${ }^{47}$ Sterling, Claire (1994): Thieves' World, Nueva York, Simon and Schuster.

${ }^{48}$ Pulido, Julia y Sansó-Rubert Pascual, Daniel: "Phenomenological Analysis of Terrorism and Organized Crime from a Comparative Criminological Perspective" Journal of Law and Criminal Justice, vol. 2, n 2 (2014), Published by American Research Institute for Policy Development. pp. 113-131.
} 
para avanzar en el desarrollo teórico-práctico de la materia, comienza paulatinamente a abrirse hacia nuevas inquietudes (quién, cómo, cuándo, para qué, con qué y qué límites), que permitirán trazar los lineamientos maestros de una futura doctrina, que posibilite articular reglamentos y protocolos para homogeneizar la labor de los diversos miembros que, formal o informalmente, conforman la estructura de seguridad (comunidad de inteligencia), destinada a combatir las manifestaciones de delincuencia organizada ${ }^{49}$.

Resulta indispensable establecer una metodología común, prácticas y procedimientos estandarizados de elaboración de productos; un glosario de términos técnicos compartido (lenguaje común); instauración de equipos multidisciplinares e interagencias; establecer la enseñanza, el reclutamiento y la política de personal; asegurar la producción de inteligencia de modo sistemático y constante; favorecer y facilitar la cooperación entre agencias; regulación de los diversos aspectos que engloban el denominado ciclo de inteligencia (planeamiento, obtención, evaluación, análisis y difusión); y la creación de controles y límites compartidos, a través de un órgano directivo de nivel nacional, estableciéndose las responsabilidades y buenas prácticas (ética) en los distintos niveles de los órganos participantes $^{50}$.

Todo ello en aras de afrontar uno de los principales retos presentes y futuros de la lucha contra la criminalidad organizada, expuesto en términos de éxito o fracaso: el recurso a la inteligencia criminal, no sólo como fundamento para la adopción de decisiones, sino también, para el soporte de la acción. Actualmente, las estrategias de disuasión focalizada y de acción selectiva ${ }^{51}$, no sólo contra las organizaciones en su conjunto o sus actividades y mercados, sino sobre sus dirigentes, buscando con ello la neutralización efectiva del fenómeno, ganan paulatinamente reconocimiento como alternativas prometedoras.

En este sentido, un asunto central es entender que el crimen organizado no se define como la existencia de una estructura específica, sino como un sistema de relaciones. La facción criminal - llámese cartel, banda, comando o mara - es la parte más visible del sistema; pero en modo alguno constituye su totalidad. Encierra, un conjunto de conexiones opacas entre el mundo legal e ilegal, con tendencia a enraizar en la esfera política e institucional.

Hipotéticamente, en circunstancias ideales, el aparato de seguridad responsable de enfrentar la delincuencia organizada, debería responder de forma uniforme y estandarizada a todas las organizaciones delictivas. Básicamente, el objeto de esta respuesta estandarizada sería garantizar la intervención equitativa del Estado frente al conjunto de la criminalidad organizada, evitando, al intervenir en todos los frentes detectados simultáneamente, favorecer a una determinada organización en detrimento de otras ${ }^{52}$.

\footnotetext{
${ }^{49}$ Sansó-Rubert, Daniel y Blanco, José María: “Inteligencia criminal”, en Giménez-Salinas, Andrea y González, José Luis (coords.) (2015): Investigación criminal. Principios, técnicas y aplicaciones, Madrid, Ed. Lid, pp. 291308.

50 Sansó-Rubert y Blanco, J. María op. cit. pp. 292-297; Ugarte, José Manuel (2011): “La actividad de inteligencia en América latina y la evolución de la inteligencia criminal”, Actividad de inteligencia y democracia en América latina, Saarbrücken, Editorial Académica Española; Sansó-Rubert, Daniel: "Estrategias de Seguridad, criminalidad organizada e inteligencia criminal: una apuesta de futuro”, en Fernández Rodríguez, José Julio; Sansó-Rubert, Daniel; Pulido, Julia y Monsalve, Rafael (eds.) (2012): Cuestiones de Inteligencia en la sociedad contemporánea, Madrid: Ministerio de Defensa-Centro Nacional de Inteligencia, pp. 204-219.

${ }^{51}$ Felbab-Brown, Vanda (2013): Modernizando la aplicación de la ley. Informe 2. Disuasión focalizada, acción selectiva, tráfico de drogas y delincuencia organizada: conceptos y prácticas. Consorcio Internacional sobre Políticas de Drogas, en https://dl.dropboxusercontent.com/u/64663568/library/MDLE-report-2 Focuseddeterrence SPANISH.pdf

${ }^{52}$ Felbab-Brown (2013): op. cit.
} 
Este postulado teórico quiebra en la práctica, cuando debemos asumir la limitación de medios y recursos disponibles para atajar las manifestaciones de delincuencia organizada. Precisamente, en este aspecto, para superar los problemas de limitación y dispersión de recursos, las estrategias de disuasión focalizada y acción selectiva cobran relevancia. Permiten centrarse selectivamente en un objetivo (neutralizar a un grupo delictivo o delincuente crónico), en un espacio geográfico acotado (Hot Spots) de dimensión variable (un barrio, una ciudad, una provincia, en todo el territorio nacional $)^{53}$, con un doble objetivo: el primario, la desarticulación de la organización o neutralización del sujeto delincuente y otro secundario, que consiste en enviar un mensaje disuasorio para el resto de organizaciones e integrantes del crimen organizado para que desistan de sus actividades delictivas, ya que paulatinamente irán ocupando el rol de objetivo ${ }^{54}$.

En lo que a las redes delictivas respecta, el quid de la cuestión radica en identificar en qué punto de la estructura de la organización o en qué momento del transcurso del ciclo criminal y de las relaciones entre grupos criminales, resultará más óptimo actuar y en qué sentido (represión, intoxicación informativa, infiltración...). Incidir, en el hecho de que, la captura de los líderes de las facciones criminales e incluso, la aprehensión de una porción importante de los integrantes de una red criminal, podrá tener un impacto temporal en las conexiones, sin que esto implique la desarticulación definitiva. Por ello, el recurso a la inteligencia criminal como apoyo a la adopción de decisiones estratégicas de interdicción selectiva y acción focalizada, constituye una necesidad a efectos de lograr intervenciones exitosas, que alcancen el máximo grado de neutralización de los objetivos.

Lógicamente, el criterio a elegir para fundamentar las estrategias de disuasión focalizada y acción selectiva (peligrosidad, daño, capacidad de infiltración institucional, capacidad de desestabilización estatal, empleo abusivo de la violencia, vínculos con organizaciones terroristas...), deberá ser objeto de evaluación en función de las circunstancias locales de cada país sobre la base de un análisis comparativo de costos, beneficios y compensaciones.

Llegados a este punto, conviene recalcar que la inteligencia criminal aporta "conocimiento" informado que permite a las autoridades anticiparse y neutralizar o disuadir las amenazas, riesgos y conflictos vinculados con la delincuencia organizada. Proteger y promover los intereses nacionales de cualquier naturaleza (políticos, sociales, económicos, mercantiles, culturales, comerciales, empresariales...), frente a la criminalidad organizada.

Un buen producto de inteligencia criminal no sólo describe cuál es la situación actual relativa al fenómeno, sino que aporta explicaciones sobre la existencia de dicho fenómeno y establece posibles evoluciones o tendencias, definiendo escenarios posibles y probables. Además, define las alternativas viables para reorientar la situación en el sentido más favorable para su erradicación y control, y establece los eventuales

\footnotetext{
53 Braga, Anthony: "The effects of hot spots policing on crime", American Academy of Political \& Social Science, $\mathrm{n}^{\circ} 578$ (2001), pp. 104-125.

${ }^{54}$ Braga, Anthony: “Getting deterrence right?", Criminology and Public Policy, vol. 11, n² (2012), pp. 201-210; Braga, Anthony y Weisburd, David: "The effects of focused deterrence strategies on crime: A systematic review and meta-analysis of the empirical evidence", Journal of Research in Crime and Delinquency, Vol. 49, n 3 (2012), pp. 323-358; Kennedy, David (2011): Don't shoot: One man, a street fellowship, and the end of violence in inner-city America. New York, Bloomsberry; Kennedy, David; Tompkins, Daniel y Garmise, Gayle: "Pulling levers: Getting deterrence right”, National Institute of Justice Journal, nº 236 (1998), pp. 2-8.
} 
costes económicos y sociales resultantes de la aplicación de dichas medidas. De la misma forma, posibilita conocer y analizar la distribución geográfica de la actividad delictiva, la concentración territorial de las organizaciones criminales (densidad criminal), el surgimiento de nuevos nichos de mercado ilícitos, la introducción de novedosas metodologías y modus operandi, nuevos productos y servicios, la identificación de las estrategias puestas en práctica por las estructuras delictivas, la familiarización con la subcultura delictiva, las características sociodemográficas relevantes de los miembros de las organizaciones criminales para su conveniente explotación (nacionalidad, región de procedencia, etnia, familia, profesión, condición de ex policías o ex combatientes, tipología de actividad ilícita en la que está especializado...), así como la detección del ascenso y caída de las organizaciones criminales, en virtud de sus fortalezas y debilidades.

De igual forma, su utilidad redunda en su empleo como un instrumento de análisis del éxito de las políticas públicas y decisiones adoptadas en la confrontación con la criminalidad organizada. Destinar capacidades de inteligencia para la realización de análisis sobre la gestión pública del Estado y el fortalecimiento institucional, con el fin de vislumbrar con la debida anterioridad, cómo determinadas decisiones sobre el manejo de lo público (recursos, bienes, y servicios), permiten o facilitan las operaciones y funcionamiento de organizaciones al margen de la ley; de tal forma, que se puedan identificar las implicaciones de las decisiones y esquemas preventivos adoptados, para evitar el fortalecimiento involuntario del crimen organizado.

Ante la magnitud de la amenaza representada por la criminalidad organizada, el desarrollo de estrategias e instrumentos más efectivos para su desarticulación, especialmente en su vertiente transnacional, así como favorecer la cooperación y la coordinación a niveles nacional e internacional, deben constituir prioridades gubernamentales para este siglo XXI. La adaptabilidad criminal demanda, al menos, la misma capacidad de adaptación de los instrumentos disponibles para garantizar la seguridad, con el fin de proveer a los organismos de seguridad de respuestas inteligentes, preventivas y proactivas, al objeto de atajar la movilización de la delincuencia organizada, ${ }^{55}$ al igual que sus capacidades de proyección estratégica $^{56}$.

A su vez, el desarrollo e implementación de una inteligencia criminal para el siglo XXI, transita indefectiblemente por cuestiones tales como el papel de la inteligencia criminal en relación a la aplicación de la ley; cuestiones legales entorno a la inteligencia criminal y su explotación; desarrollo y aplicación de nuevas metodologías, técnicas y modelos; articulación de redes y flexibilización de estructuras; creación de una comunidad o subcomunidad de operadores de inteligencia criminal; ampliación de los posibles escenarios de explotación de esta herramienta de análisis y conocimiento: prisiones $^{57}$, apoyo a la adopción y planificación

\footnotetext{
${ }^{55}$ Sansó-Rubert Pascual, Daniel: "Inteligencia criminal. Una elección estratégica en clave de seguridad frente a la iniciativa de la delincuencia organizada", en Rivera, Fredy (coord.) (2011): Inteligencia estratégica y Prospectiva, Quito, Flacso-Senain-AECID, pp. 215-238.

${ }^{56}$ Organizaciones criminales como las rusas empleando tácticas y estrategias de inteligencia surgidas de sus gabinetes de información formados por personas que anteriormente pertenecieron a los servicios de seguridad, Policía, KGB o GRU. Sirva como ejemplo la pertenencia de oficiales del KGB como Aleksander Novikov a la organización Solntsevo, o de Grigory Gusiatinsky que pasó desde el servicio a liderar el grupo criminal Orekhovskaya. O el nombramiento del coronel del KGB Filip Bobkov, como jefe de seguridad del oligarca Gusinsky. López, op. cit, p. 5.

57 Sansó-Rubert Pascual, Daniel: "Inteligencia criminal y sistemas penitenciarios: algunas reflexiones", Monográfico Inteligencia criminal, URVIO, Revista Latinoamericana de Estudios de Seguridad, $\mathrm{n}^{\mathrm{o}} 15$ (2015), Quito, Facultad Latinoamericana de Ciencias Sociales (FLACSO), pp. 98-111.
} 
de acciones focalizas y de interrupción selectiva ${ }^{58}$, comprensión de las subculturas delictivas, estudios de antropología criminal social y cultural..., así como toda suerte de desafíos que puedan plantearse al respecto ${ }^{59}$.

Esto requiere de cambios en las actitudes y formas de pensar la seguridad (cambio de paradigma a favor de la seguridad proactiva), y de explotación de las capacidades de inteligencia criminal. Sin estos cambios, las redes criminales seguirán capitalizando la iniciativa.

\footnotetext{
${ }^{58}$ Felbab-Brown (2013): op. cit.

${ }^{59}$ Sansó-Rubert y Blanco, op. cit., p. 307.
} 